\title{
Reconstruction of the North Atlantic end-member of the Atlantic Meridional Overturning Circulation over the last 2 Myr
}

\author{
J. KIM ${ }^{1 *}$, S. L. GOLDSTEIN ${ }^{1}$, L. D. PENA ${ }^{2}$, M. \\ JAUME-SEGUI $^{2}$, M. YEHUDAI ${ }^{1}$ \\ ${ }^{1}$ Lamont-Doherty Earth Observatory of Columbia \\ University, USA (*correspondence: \\ jk3652@columbia.edu) \\ ${ }^{2}$ Department of Earth and Ocean Dynamics, University of \\ Barcelona, Spain
}

North Atlantic Deep Water (NADW) represents the major water mass that drives the Atlantic Meridional Ocean Circulation (AMOC), which undergoes substantial reorganization with changing climate. In order to understand its impact on ocean circulation and climate through time, it is necessary to constrain its composition. We report $\mathrm{Nd}$ isotope ratios of Fe-Mn oxide encrusted foraminifera from DSDP Site $607(41.00 \mathrm{~N} 32.96 \mathrm{~W}, 3427 \mathrm{~m})$, in the present-day core of NADW. We provide a new North Atlantic paleocirculation record covering the last $2 \mathrm{Myr}$.

Results for the last $2 \mathrm{Myr}$ show that Site 607 interglacial $\varepsilon_{\mathrm{Nd}}$-values are consistently similar to present-day NADW ( $\varepsilon_{\mathrm{Nd}}$ $\sim-13.5$ ), with median $\varepsilon_{\mathrm{Nd}}$-values of -14.2 and -13.9 in the early and mid-late Pleistocene. Glacial $\varepsilon_{\mathrm{Nd}}$-values are higher by $\sim 1 \varepsilon_{\mathrm{Nd}}$-unit in the early Pleistocene, and $\sim 2 \varepsilon_{\mathrm{Nd}}$-units in the mid-late Pleistocene.

We interpret the North Atlantic AMOC source as represented by the Site 607 interglacial $\varepsilon_{\mathrm{Nd}}$-values, which has remained nearly stable throughout the entire period. Glacial $\varepsilon_{\mathrm{Nd}}$-values reflect incursions of southern-sourced waters to Site 607 , which is supported by coeval shifts to lower benthic $\delta^{13} \mathrm{C}$.

A period of greatly disrupted ocean circulation marks 2950-850 Ma, which may have been triggered by enhanced ice growth in the Northern Hemisphere that began around $\sim 1.2 \mathrm{Ma}$, as suggested by possible input events of $\mathrm{Nd}$ from the surrounding cratons into the North Atlantic observed in Site 607. Interglacial AMOC only recovers to the previously observed vigor over $200 \mathrm{kyr}$ following the disruption, whereas further intensified SSW incursion into the deep North Atlantic come to characterize the mid-late Pleistocene glacial intervals. 